positions of solids, for example, of lithium aluminium hydride $e^{4}$ and of mercury fulminate ${ }^{5}$.

R. A. W. HILL

A. A. Waltace

Research Department,

Nobel Division,

Imperial Chemical Industries, Ltd.,

Stevenston, Ayrshire. May 9.

1 Hill, R. A. W., Proc. Roy. Soc., A, 226, 455 (1954).

2 Darwin, C. G., Phil. Mag., 27, 315, 675 (1914). Cottrell, A. H., "Dislocations and Plasticklow in Crystals" (Clarendon Press, Oxford, 1953). See also, Amelinckx, S., Phil. Mag., (8), 1, No. 3, 269 (1956). Humphreys-Owen, S. P.' F., Proc. Phys. Soc., B, 69, 350 (1956).

${ }^{3}$ Spice, J. F., and Staveley, L. A. K., J. Chem. Soc. Indust., 68, 313 (1949).

- Garner, W. E., and Hailes, H. R., Proc. Roy. Soc., A, 139, 576 (1933).

-Garner, W. E., and Haycock, E. W., Proc. Roy. Soc., A, 211, 335 (1952).

\section{Mass-Spectrometric Detection of the Ion $(\mathrm{SrOK})^{+}$}

IN a study of the ionization produced by traces of alkali and alkaline earth elements in hydrogen/air flame gases, Wheeler ${ }^{1}$ has found evidence for ions of the type $(B O A)^{+}$, where $A$ represents an atom of alkali metal and $B$ one of alkaline earth. 'Theoretical calculations, by the method of Rittner'2, suggest that such ions should be of high stability in the gas phase, the heat of dissociation into $B O$ and $A^{+}$being of the order of $100 \mathrm{k.cal} . / \mathrm{mole}$. A mixed ion of this type was suggested by the highly specific behaviour given by various $A / B$ pairs. The basic measurements were, however, of electron concentrations, the existence of this particular positive ion being inferred from them, and it seemed desirable to have independent and more direct evidence for their presence.

An attempt to obtain and identify such ions has been made by mass-spectrometric analysis of the ionic content of the vapour from a strongly heated mixture of a potassium and a strontium salt in a vacuum oven. The diagram of the oven is shown in Fig. 1. The oven cell $(A)$, of molybdenum, was constructed in two pieces, rammed together after loading with the charge $(B)$. It was maintained at a potential of $+1,500 \mathrm{~V}$. (stabilized) relative to the remainder of the oven, this serving to accelerate the ions into the mass spectrometer, and also allowing the front end to be heated to the required temperature by electron bombardment from the filament $(C)$. A second filament $(D)$ allowed of further heating (of the rear end) by radiation. The temperature of the front (exit) end of the oven was determined pyrometrically, and that of the rear by a thermocouple $(E)$, which also carried the emission current, via the oven, from $(C)$. The inner radiation shields $(F, G)$ were of nickel, and the outer, water-cooled, shield $(H)$ was of copper.

Any positive ions in the vapour from the charge were repelled from the oven, through the slit system, into a mass spectrometer, which was a $90^{\circ}$ Nier type. An electron multiplier detection system was used so that actual counts of ions could be made. A mixture of strontium and potassium carbonates was heated, a little cæsium being added to give a reference peak at mass 133. With this mix ture, the rear of the oven being at about $1,000^{\circ} \mathrm{K}$., and the tip at about $1,900^{\circ} \mathrm{K}$., which were found to be optimum working conditions, an ion current was noted at mass 143 . This was not evident with either of the carbonates

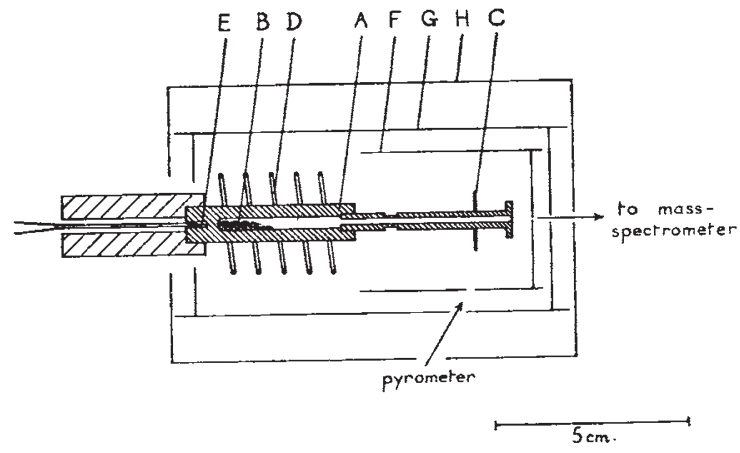

Fig. 1

heated alone under the same conditions. It corresponds with a positive ion $\left({ }^{88} \mathrm{Sr}^{16} \mathrm{O}^{39} \mathrm{~K}\right)^{+}$, which combines all the most abundant isotopes, and should give at least eight times as large a peak as any other combination. The observed peak corresponded with a current of about twelve ions per sec., with a noiselevel of about two per sec., so that no other (SrOK) ${ }^{+}$ peak would be expected.

It is considered that this provides reasonable evidence for the existence of this type of ion, first postulated in the flame studies referred to. The ions probably owe their stability to the very large electrostatic attraction between the alkali metal ion $A^{+}$and the large dipole of the alkaline earth oxide $B O$. It is interesting to note that Inghram, Chupka and Porter $^{3}$, also using a mass-spectrometric method, have been able to demonstrate the formation of the ion $\left(\mathrm{Ba}_{2} \mathrm{O}\right)^{+}$from the vapour of barium oxide heated in an alumina crucible.

One of us (P.F.K.) is grateful to the Department of Scientific and Industrial Research for a grant covering the period of this investigation.

T. M. SUGDEN

P. F. KNEWSTUBB

K. F. SмIтн

Department of Physical Chemistry, and

Cavendish Laboratory,

Cambridge.

May 28

${ }^{1}$ Sugden, T. M., and Wheeler, R. C., Disc. Farad. Soc., 19, 76 (1955). 2 Rittner, E. S., J. Chem. Phys., 19, 1030 (1951).

${ }^{8}$ Inghram, M. G., Chupka, W. A., and Porter, R. F., J. Chem. Phys., 23, 2159 (1955).

\section{Isolation of the Stable Boron Trifluoride - Hydrogen Fluoride Complexes of the Methyl- benzenes ; the Onium Salt (or $\sigma$-Complex) Structure of the Friedel-Craits Complexes}

'TxE alkylation of aromatic hydrocarbons catalysed by aluminium chloride and similar Friedel-Crafts catalysts is ordinarily accompanied by the formation of deeply coloured oily liquids of high density. The structure of these 'Friedel-Crafts complexes' has been investigated by a number of workers ${ }^{1}$. H. C. Brown and H. W. Pearsal ${ }^{2}$ have proved the formation of a molecular complex from toluene and aluminium chloride-hydrogen chloride at low-temperature. In further work, H. C. Brown and J. D. Brady ${ }^{3}$ have established the structure of the hydrogen chloride-aluminium chloride complexes of the methylbenzenes as $\sigma$-complexes in contrast to the proposed hydrogen chloride complexes which have 